\title{
Usos de si no ensino remoto emergencial: A atividade docente sob os enfoques dialógico e ergológico
}

\author{
Use of the self during emergency remote teaching: professional teaching activities under ergology and \\ dialogical approaches
}

\section{Márcia Cristina Neves Voges}

Pontifícia Universidade Católica do Rio Grande do Sul - PUCRS - Rio Grande do Sul - Brasil

\section{Maria da Glória Corrêa di Fanti}

Pontifícia Universidade Católica do Rio Grande do Sul - PUCRS - Rio Grande do Sul - Brasil

\begin{abstract}
Resumo: O presente artigo problematiza a atividade laboral do professor no que diz respeito ao enfrentamento do trabalho a distância, em home office, no contexto emergencial exigido pela pandemia do novo coronavírus (COVID-19). Tendo como pressupostos teóricos a perspectiva dialógica do discurso e a abordagem ergológica do trabalho, esta investigação visa a analisar características das dramáticas de uso de si na atividade de professores que exerciam a docência presencial e que passaram ao ensino remoto. Para tanto, são analisados quatro depoimentos de professores do ensino básico, publicados em reportagens divulgadas no G1 e no UOL, em junho de 2020. Os resultados contribuem para o (re)conhecimento dos debates de normas e valores que afetam o professor no ensino remoto e, consequentemente, para possíveis transformações das próprias práticas laborais no pós-pandemia.
\end{abstract}

Palavras-chave: Usos de si. Ensino remoto emergencial. Atividade docente. Dialogismo. Ergologia.

\begin{abstract}
This paper analyzes professional activities of teachers facing remote work under a home office regime in an emergency context of novel coronavirus (COVID-19) pandemic. Based on a dialogical approach to discourse and on ergology, this research seeks to analyze the dramatic use of the self in activities of teachers who worked on-site and had to move to remote teaching. To reach that goal, we analyze four testimonials from primary education teachers published in Brazilian news portals G1 and UOL in June 2020. Our results contribute to the debates on uncovering and acknowledging norms and values affecting teachers working in remote teaching regimes and consequently to possible changes to work practices after the pandemic.
\end{abstract}

Keywords: Use of the self. Emergency remote teaching. Professional teaching activities. Dialogical Approach. Ergology. 


\section{Considerações Iniciais}

A educação, inserida nas diferentes esferas de atividade, passa por um momento tenso, tendo em vista as mudanças nas rotinas sociais provocadas pela pandemia do novo coronavírus. Esse vírus, que surgiu na China e que passou por diversos países, chega ao Brasil dividindo opiniões sobre tratamento, cura e cuidados. Nesse cenário, para driblar os contágios e as mortes em massa, o isolamento social tornou-se o cuidado fundamental no auxílio à diminuição da contaminação da população. Essa atitude levou as escolas e as instituições de ensino a fecharem as portas e passarem a atender alunos e comunidade escolar via educação remota com caráter emergencial. A quebra na regularidade da rotina de atividades docentes presenciais, desde a educação infantil até a educação superior, levou professores a travarem uma batalha para manter as especificidades do seu trabalho com o ensino presencial, de forma que suprissem a distância as propostas pedagógicas encapsuladas pelas tecnologias para o ano letivo de 2020.

A disseminação da contaminação pela COVID-19 conduziu o ensino presencial a mudar a rota, e, em 29 de maio de 2020, nos termos do artigo $2^{\circ}$ da Lei no 9.131, de 24 de novembro de 1995, o Ministro da Educação homologou o parecer CNE/CP n 5/2020, do Conselho Nacional de Educação (CNE), "o qual aprovou orientações com vistas à reorganização do calendário escolar e à possibilidade de cômputo de atividades não presenciais, para fins de cumprimento da carga horária mínima anual" (BRASIL, 2020). A partir desse momento, os docentes tiveram que adaptar posturas, metodologias e habilidades e ainda testar capacidades relacionadas às tecnologias digitais da informação (TICs) no trabalho, implantandoas na sua rotina como meio efetivo de comunicação com os alunos.

Em tal cenário, professores são postos à prova na sua atividade profissional. Eles precisam se adaptar a outras maneiras de ensinar, amolgados pelas tecnologias. Por conseguinte, espera-se dos alunos "uma integração com o novo instrumento de aprender" e dos professores o investimento na "ideia de que a essência de educar é acompanhar essas transformações que ocorrerem [...]" (LEITE; VOGES, 2020, p. 21) na educação. Por sua vez, os alunos, potencialmente imersos no mundo tecnológico para lazer e diversão, passam a enfrentar uma tecnologia educadora. Instala-se, assim, de imediato, um espaço virtualizado entre eles, educacional, pedagógico e social-virtual. Entretanto, esse espaço é constituído por conhecimentos distintos e experiências variadas com relação às tecnologias, o que remete, por exemplo, aos nativos e aos imigrantes digitais, seguindo o entendimento de Prensky (2001). Também remete à relação de ubiquidade (WEISER, 1991), que, por um lado, pressupõe a presença direta e constante da informática e da tecnologia no cotidiano das pessoas, e, por outro, não garante que a usabilidade das ferramentas seja igual para cada um dos usuários. O trabalho do professor, em sua constituição multifacetada, é permeado por demandas que abrangem desgastes físicos e mentais próprios da profissão e revelam uma atividade baseada nos usos de si (por si e pelo outro), num complexo fazer industrioso. Conforme Schwartz (2014, p. 261), "toda sequência de atividades industriosas envolve arbitragens, debates, imersos num mundo social em que a comunidade de destino é sempre eminentemente problemática, em permanente reconstrução". Nesse fazer industrioso, o fazer docente também se vincula ao seu campo de formação, e muitas interrogações sobre do que se constitui a natureza do seu conhecimento "parecem indicar uma relação problemática entre os professores e os saberes" (TARDIF, 2017, 32), o que, em consequência, reverbera no desenvolvimento do seu trabalho.

Nessa perspectiva, tendo em vista a formação docente e as exigências do contexto pandêmico, a presente reflexão tem como objetivo analisar características das dramáticas de uso de si na atividade de professores que exerciam a docência presencial e que passaram ao ensino remoto emergencial. É nesse sentido que a pesquisa visa contribuir para o (re)conhecimento dos debates de normas e valores que afetam o professor no ensino 
remoto e, consequentemente, para possíveis transformações das próprias práticas laborais no póspandemia.

Sendo o modelo presencial tradicionalmente pautado pela relação de proximidade física entre o professor e o aluno, a prática de ensino remoto instaura estranhamento e desafios, exigindo conhecimentos tecnológicos e novas formas de interação, que, embora não substitua a modalidade presencial, proporcione a continuidade dos estudos e a aprendizagem decorrente. Com isso, na esteira das experiências vivenciadas pelo professor, como é o caso do ensino remoto emergencial, ao "se considerar o trabalho [docente] como atividade, reconhece-se o caráter enigmático de quem trabalha" (DI FANTI, 2014, p. 255), as dramáticas de usos de si e o debate de normas e de valores postos em jogo. A discussão dessas questões, buscando compreender facetas dessa dramaticidade, pode contribuir, ainda que modestamente, para reflexões sobre os rumos da educação brasileira no pós-pandemia.

Como fundamentação teórica, a presente pesquisa ancora-se na perspectiva dialógica do discurso e na abordagem ergológica do trabalho, uma vez que tais pressupostos têm como "centro de reflexão a atividade humana, seja na dimensão linguageira, seja na laboral" (DI FANTI, 2012, p. 311). Nesse sentido, tendo em vista o contexto do ensino remoto permeado por tecnologias, exercido em regime emergencial durante a pandemia, selecionamos para análise quatro depoimentos de professores do ensino básico divulgados nas plataformas jornalísticas G1 e UOL, em junho de 2020. Para tanto, entendendo o trabalho do professor como uma atividade enigmática, que pode ser observável, mesmo que parcialmente, a partir da linguagem em sua constituição dialógica e axiológica, consideramos o objeto de estudo em sua singularidade, heterogeneidade e inconclusividade.

Sob esse enfoque, esta investigação, de caráter qualitativo, está organizada em três seções seguidas das considerações finais. A primeira seção

1 O Círculo de Bakhtin é formado por um grupo de estudiosos, cujos principais integrantes da área da linguagem são Mikhail Bakhtin, Valentin Volóchinov e Pável Medviédev, que tinham interesses filosóficos contempla a perspectiva dialógica do discurso; a segunda, a abordagem ergológica do trabalho. A terceira, voltada para a parte analítica, dedica-se a discutir as dramáticas de uso de si na atividade dos professores no ensino remoto emergencial.

\section{Perspectiva dialógica do discurso: a singularidade do ato}

O Círculo de Bakhtin tem como pressuposto epistemológico de base o dialogismo, princípio que tem no outro a condição de existência do sujeito, do discurso e dos sentidos. ${ }^{1}$ A partir dessa constitutiva relação com o outro, Bakhtine (2003) discute o ato humano como um evento único do ser, que pressupõe uma atividade participativa, axiológica e dialógica do sujeito, não permitindo outra posição que não seja responsiva e responsável. Reconhece-se, assim, o não-álibi no ser, que é entendido na concretude única do ato como o reconhecimento da singularidade da participação do ser, a sua insubstituibilidade.

Essas observações, associadas ao contexto imposto pela pandemia, apontam para o professor como um sujeito em processo, inscrito em um dado tempo-espaço, complexo, que, nas variadas interações, vai se constituindo como um professor único, com uma experiência singular diante de uma dada realidade. Nessa perspectiva, concebe-se o sujeito como dialógico que, não apagando a historicidade que o sustenta e singulariza seu dizer heterogêneo, não absorve uma só voz social, mas sempre muitas vozes: é "um agitado balaio de vozes sociais e seus inúmeros encontros e entrechoques [...] o mundo interior é uma arena povoada de vozes sociais em suas múltiplas relações de consonâncias e dissonâncias; e em permanente movimento" (FARACO, 2009, p. 84).

A observação do dizer do professor, nesse cenário, é um meio de acessar sua experiência particular e características de sua atividade de trabalho diante de um quadro geral que abrange o coletivo dos

comuns e se reuniam, na Rússia, para debater suas ideias, principalmente entre 1919 e 1929 (FARACO, 2009). 
profissionais de educação. Enunciar, para o Círculo de Bakhtin, é responder, ou seja, é se posicionar ativamente frente ao outro, sendo que a palavra, conforme Volóchinov (2017, p. 181), mostra as posições axiológicas do dizer, pois "está sempre repleta de conteúdo e de significação ideológica ou cotidiana". Sob esse enfoque, o sujeito vive "em um mundo de palavras do outro" e "toda a [sua] vida é uma orientação nesse mundo; é reação às palavras do outro [...]" (BAKHTIN, 2011, p. 379).

O discurso, desse modo, emerge de uma diversidade de posicionamentos sociais em interrelação. Nesse meio dialogizado, agitado e tenso de avaliações, o discurso, em um momento histórico e social determinado, entrelaça-se com uns, afasta-se de outros, cruza-se com terceiro, tocando em "milhares de linhas dialógicas vivas envoltas pela consciência socio-ideológica no entorno de um dado objeto da enunciação, não [podendo] deixar de ser participante ativo do diálogo social" (BAKHTIN, 2015, p. 49). Associando essas observações à atividade docente focalizada nesta reflexão, temos de considerar o meio dialogizado de discursos que perpassam as condições de trabalho em um cronotopo (espaço-tempo) marcado, em sentido amplo, por uma crise de saúde pública mundial, que não esconde os aspectos políticosociais degradados pelas instâncias governamentais e, em sentido estrito, as situações adversas que atingem a educação brasileira e que são intensificadas na pandemia.

Dentre os impasses vividos, docentes enfrentam o home office ou teletrabalho sem ter se preparado para essa função. Jornadas de trabalho mediadas com ou sem acesso à internet, materiais impressos, PDFs, computadores e/ou smartphones, grupos em Whatsapp, Classroom, Moodle, Teams, Zoom, entre outros nomes de aplicativos e plataformas, passaram a ocupar as verbalizações diárias dos professores. Nesse meio dialogizado de discursos, novos termos se incorporam ao cotidiano e desafiam os professores a compreendê-los dentro do seu contexto de vida e trabalho. Tais palavras até pouco tempo apenas orbitavam seu cotidiano escolar, mas não implicavam diretamente o seu trabalho, como implicam agora. Assim, dialogam com embates sociais, históricos e ideológicos de uma existência que "não apenas é refletida no signo, mas também é refratada nele" (VOLÓCHINOV, 2017, p. 112).

$A$ incorporação de diferentes recursos à educação, como WhatsApp, smartphone e e-mail, por exemplo, faz emergir signos ideológicos, oriundos das relações interindividuais. Segundo Volóchinov (2017, p. 94), o signo ideológico pode gerar uma multiplicidade de outros signos, sendo "tanto ele mesmo, quanto todos os efeitos por ele produzidos, ou seja, aquelas reações, aqueles movimentos e aqueles novos signos que ele gera no meio social circundante, ocorrem na experiência externa". Nessa dinâmica, cada campo da criação ideológica possui seu próprio modo de refletir (descrever) e refratar (interpretar) a realidade nas interações sociais.

A palavra, para Volóchinov (2017, p. 140), é um signo ideológico por excelência, uma vez que há nela ênfases sociais multiacentuadas que "se confrontam e entram em embate. Uma palavra no lábio de um único indivíduo é um produto da interação viva das forças sociais". A dialética do signo, associada à alteridade e ao dialogismo, garante ao enunciado uma permanente tensão entre sujeitos e discursos, que se constituem e se alteram na relação com outros sujeitos e outros discursos (passados, presentes e futuros). Nessa dinâmica, de acordo com Medviédev (2012, p. 185), o ato de compreensão exige a observação da "atmosfera axiológica e sua orientação avaliativa assumida no meio ideológico [...] no contexto da sua contemporaneidade". O discurso, desse modo, traz em sua constituição diálogos com outros discursos, revelando embates entre signos ideológicos e valores sociais.

A entonação, conforme Volóchinov (2019, p. 123), "sempre está no limite entre o verbal e o extraverbal, entre o dito e o não dito". Pela entonação, "a palavra entra em contato direto com a vida", e o falante com os ouvintes, o que legitima a entonação como "social par excellence", já que é sensível às diferentes "oscilações do ambiente social que circunda o falante". Nesse caminho, a entonação pressupõe um "coro de apoio", observável pela construção do 
enunciado e pelo "caráter compartilhado e subentendido das avaliações" sociais (VOLÓCHINOV, 2019, p. 124).

Seguindo as observações de Volóchinov (2017, p.111), "somente aquilo que adquiriu um valor social poderá entrar no mundo da ideologia, tomar forma e nele consolidar-se". No caso do ensino remoto, os signos ideológicos engendram dimensões valorativas nos discursos que circulam, articulando o campo da educação ao das tecnologias. Nesse contexto, a perspectiva dialógica orienta a análise da linguagem, o discurso nas interações sociais, tendo em vista o sujeito e a "vida do discurso", para usar as palavras de Bakhtin (2017, p. 207), que se mostra em sua complexidade multifacetada, cujos atos se hibridizam em um dado cronotopo e num contexto sócio-histórico ímpar, que tem no cerne a atividade humana de trabalho.

\section{Abordagem ergológica do trabalho: a irrepetibilidade da atividade}

A abordagem ergológica, como entende Schwartz (2016), volta-se para os debates de normas e de valores que renovam indefinidamente a atividade humana de trabalho. Nessa esteira, a atividade de trabalho, em sua complexidade, nunca se repete integralmente, pois sempre há variabilidades, mesmo que mínimas. Embora se reconheça a importância das normas antecedentes (leis, regulamentos, orientações em geral etc.) para o exercício profissional, entende-se que sempre haverá renormalizações, isto é, sempre o trabalhador fará diferente do que é prescrito (SCHWARTZ, 2016; DURRIVE, 2015).

Ao considerar o trabalho como uma atividade complexa, industriosa, a ergologia convoca uma diversidade de disciplinas para abordá-lo, como filosofia, ergonomia da atividade, linguística, psicologia etc. No âmbito da linguística, Schwartz (2016) ressalta a necessidade daquelas perspectivas que focalizam o enunciado, a enunciação, o aqui e agora no momento do viver e do trabalhar, como se vê na proposta bakhtiniana, em que a dimensão irrepetível do ato pode contribuir, por conseguinte, para a compreensão da singularidade na situação de trabalho.

Nessa proposição, Schwartz (2016, p. 231) observa a relação entre o falar e o corpo-si, considerando o corpo-si como uma espécie de sedimentação de renormalizações que (re)transforma um pouco esse corpo-si. "Falar é uma maneira de dialogar com o seu corpo-si frente a uma situação que sempre é, por uma parte, inédita". Essa dimensão da linguagem do corpo-si, que é constituído do cruzamento dos debates de normas, deve ser "aprofundada com o apoio dos linguistas" que se dedicam a olhar a enunciação. O debate de normas é atravessado pelo mundo de valores e implica "não só a saúde mas todas as dimensões do corpo-si", uma entidade enigmática que indissocia o corpo físico e a mente, abrangendo interações sociais, memória, emoções, posição postural etc. (MACHADO; DI FANTI, 2013).

No que tange ao trabalho docente, Saujat (2004) observa que, embora se tenha diferentes pesquisas sobre o papel do professor no processo ensino-aprendizagem, pouco se tem explorado sobre o ensino como trabalho. Sob esse enfoque, Faïta (2005, p. 117) destaca que “o 'trabalho' de professores ainda é raramente considerado como tal", uma vez que pouco se exploram "os modos como o professor se investe na realização das tarefas assim como a intensidade desse investimento". Esses questionamentos, que já nos motivaram a refletir sobre o direcionamento da atividade do professor-estagiário (HINZ; DI FANTI, 2013), agora nos motivam a analisar aspectos da atividade do professor no ensino remoto emergencial em contexto pandêmico.

Nesse sentido, entende-se que problematizar o trabalho docente frente ao contexto epidemiológico é convocar uma reflexão sobre práticas profissionais, constituídas pelas tensões entre o visível e o invisível, tal qual proposto por Schwartz (2011). Dentre as tensões pressupostas, a relação entre teoria e prática sempre emerge nos conflitos inerentes à atividade docente, tendo em vista se considerar que a formação e/ou aperfeiçoamento do professor teria uma relação direta com a sala de aula, ou seja, a formação estaria 
para o prescrito e a prática estaria para o real. No entanto, ainda que o professor procure seguir as normas antecedentes (teoria, legislação, orientações da instituição de ensino etc.), sempre renormalizará, fará diferente do que o planejado. Se, por um lado, a cobrança e a pressão de fazer "exatamente" como o prescrito, leva ao adoecimento, já que o ser humano não é uma máquina, por outro, a falta de normas e/ou a falta de tempo de conhecê-las para o exercício profissional, como o que estamos vivendo, também pode gerar sintomas, como ansiedade, impotência etc.

Seguindo a abordagem ergológica, Machado e Di Fanti (2013, p. 26) observam que que "as pessoas praticam, o tempo todo, uma gestão de si como uma questão humana que envolve escolhas, valores, arbitragens", já que a gestão é própria do humano, da ordem da vida. Por isso, o trabalhador, ao fazer uso de si, arrisca e pode acertar ou falhar, o que caracteriza a dinamicidade da vida. Nesse trabalho como uso,

o outro participa tanto no contato direto e real quanto nas nossas decisões, pois, no momento em que escolhemos um caminho, ele nada mais é do que uma resposta ao que já vimos outros fazerem ou por aquilo que esperamos ouvir de outros. É preciso buscar esse uso de si por si onde se encontram forças aliadas, afirmadoras da vida; é aí que o sujeito lança mão de si mesmo para solucionar seus dilemas, sendo, por isso, responsável por suas decisões e arbitragens (MACHADO; DI FANTI, 2013, p. 26).

$\mathrm{Na}$ relação com o outro, o professor, no contexto do ensino remoto emergencial, se depara com vários embates. O "como fazer" passou a "ditar" o agir dos professores, e as lives passaram a ocupar cada vez mais a vida dos docentes; tudo isso para que eles pudessem entender "onde" deveriam trabalhar, um espaço complexo, que, mesmo não tendo como substituir integralmente a sala de aula presencial, dela não podiam prescindir. Nessa extenuante transição na trajetória educativa online, o professor, sabendo "por que" tinha de migrar para o ensino remoto, teve de se deparar com um "para quem", também complexo, arquitetado nas figuras da instituição de ensino (particular e/ou pública) e do aluno, além dos diferentes estratos da sociedade, que exigiam respostas imediatas no atendimento à comunidade escolar. Esses desafios remetem à infidelidade do meio, em que de "um dia para o outro, ou de uma situação de trabalho a outra", parte ou tudo pode mudar (SCHWARTZ; DURRIVE, 2010, p. 189). As mudanças ocorridas com o regime de urgência implantado mostram que os professores, por um lado, procuraram dar continuidade ao ensino presencial, como enviar e receber, fazer e devolver, corrigir e avaliar diferentes atividades, e, por outro, entraram em embate com o ensino remoto e suas "regras e prescrições impostas pela instituição", para usar as palavras de Amigues (2004, p. 38), devido às diferentes limitações e desafios encontrados.

Dentre as diferentes imposições institucionais, os professores passaram a lidar com ferramentas desconhecidas, o que remete a um processo de breve retorno ao início de sua carreira ao buscar reaprender a ensinar, a buscar novas metodologias para 0 exercício do seu trabalho de modo a alinhar atividades para o aluno tornar-se "[agente] da sua própria concepção" (AMIGUES, 2004, p. 45). Os debates de normas, como prevê a ergologia, são complexos e resultam de emaranhados de renormalizações, sempre locais, renovados incessantemente, impossíveis de serem antecipados (SCHWARTZ, 2016; DI FANTI, 2019). Por conseguinte, ainda que o trabalho físico e intelectual dos professores seja exaustivo, qualquer movimento de formação poderá auxiliar na transformação do cenário da educação. Nesse âmbito, cada trabalhador, ao renormalizar, relaciona-se com características da situação e com maneiras de conceber a saúde e os valores. Assim, os usos de si por si e pelo outro são pistas a serem observadas para a compreensão da atividade laboral, em geral, e da atividade docente, em particular.

Usos de si no ensino remoto emergencial: um enfoque ergo-dialógico

Para a análise das verbalizações docentes, tomamos o artigo Linguagem e trabalho: diálogo entre a translinguística e a ergologia (DI FANTI, 2012), que, 
além de aproximar a perspectiva dialógica e a abordagem ergológica, discorre sobre a importância da verbalização do trabalhador para o (re)conhecimento da complexidade da atividade laboral.

Essa constatação está de acordo com as ponderações de Schwartz (2010, p. 134, 135) que entende que a reflexão sobre as dramáticas de uso de si exige a observação da linguagem, (i) seja voltada para a linguagem do cotidiano do trabalho, "tomada na horizontalidade da atividade", em que "o trabalhador a utiliza para regular sua atividade", (ii) seja voltada para uma dimensão "mais distanciada em relação à história e à atividade" (p. 139). Nessa direção, Faïta (2002) destaca a importância do estudioso da linguagem para a análise do trabalho, tendo em vista a necessidade de se observar movimentos discursivos e sucessivos efeitos de sentido no âmbito dos diálogos empreendidos.

Sob a perspectiva dialógica, além de considerar a situação em que as verbalizações foram produzidas, observam-se os signos inter-relacionais, elásticos, as palavras e seus dinâmicos acentos valorativos (DI FANTI, 2012). Nas verbalizações, o ser aparece refletido e refratado no signo, já que nele se confrontam índices de valor contraditórios, coexistência de diferenças e posições ideológicas (VOLOCHINOV, 2017), o que pode ser associado ao debate de normas e valores da atividade industriosa do professor.

No que se refere ao contexto desta investigação, que, embasada na perspectiva dialógica e na abordagem ergológica, tem como foco a análise das dramáticas de uso de si do professor que foi convocado ao ensino remoto em função da pandemia, buscamos na web, no mecanismo de pesquisa do Google, pela temática "trabalho docente na pandemia". Essa busca tinha o propósito de identificar reportagens que tivessem em sua chamada as palavras-chave para este trabalho: professores, trabalho e pandemia/ Coronavírus. A pesquisa recuperou registros que estavam relacionados ao nosso propósito investigativo em alguns sites, mais precisamente em duas plataformas jornalísticas: G1, com o título "Professores relatam mais trabalho em nova rotina de ensino pela internet durante pandemia" , e UOL, com o título "Coronavírus: professores falam dos desafios e vantagens de trabalhar em casa", ambas publicadas em junho de 2020. A reportagem do G1 apresenta relato de uma professora do ensino básico de Poços de Caldas (MG) sobre o trabalho no período da pandemia. A reportagem do UOL apresenta depoimentos de professores, também do ensino básico, de diferentes cidades e estados, como Goiânia (GO) e São Paulo (SP).

Em razão do recorte e da seleção das reportagens pelas palavras-chave, selecionamos quatro excertos (E1, E2, E3, E4) que se constituem por depoimentos de professores que foram entrevistados para a construção das reportagens.

Excerto 1 - (G1): professora Fernanda

"A preparação das aulas leva um tempo maior. Hoje, com sistema remoto, o professor trabalha três vezes mais. Temos que fazer slides e criar mais exercícios, porque a aula online rende mais, é mais rápida".

"Há professores mais novos que dominam muito bem a tecnologia, mas há também professores que não dominam nada. Eu vejo que é desafiador a todo tempo. Se dá alguma coisa errada, a gente fica assustado, entra em desespero. Mas a cada dia vou me sentindo mais segura e preparada. É um período curto para muitas adaptações. Foi difícil no começo, mas agora estamos começando a dominar melhor os instrumentos tecnológicos para promover aulas mais significativas para os alunos".

Excerto 2 - (UOL): professora Helivânia

"Existe a dificuldade em aprender a utilizar novas ferramentas e o fato de muita coisa ser cobrada, em um curto período de tempo. Sobre as novas tecnologias utilizadas, por exemplo, eu posso citar o fato de que muitas pessoas têm facilidade em falar com multidões, mas falar para uma câmera é algo totalmente diferente e desafiador".

Excerto 3 - (UOL): professor Vinicius

"Os horários são os mesmos de antes da pandemia. Há mais trabalho porque precisamos preparar aulas em um outro formato, mas cada vez mais nos adequamos melhor ao novo modelo".

Excerto 4 - (UOL): professor Rafael

"O volume de trabalho aumentou bastante depois do regime de aulas a distância. Como eu não estava acostumado com esse tipo de trabalho, tive que aprender a utilizar muitas ferramentas, sem falar que o formato das atividades feitas a distância é 
bastante diferente das feitas em sala de aula e isso é bastante desafiador".

"Acho que a maior desvantagem é que o acesso à internet ainda é limitado para alguns alunos, principalmente de baixa renda".

Para a análise, consideramos o professortrabalhador como um ser em processo integrado às interações sociais que, em seu dizer, reflete e refrata valores, saberes e debate de normas que orientam para as dramáticas de uso de si a serem observadas. Considerando os excertos destacados, selecionamos dois pontos complexos a serem discutidos, que perpassam todos os depoimentos: (i) o tempo e a intensidade do trabalho, e (ii) as tecnologias e os desafios da formação.

O tempo e a intensidade do trabalho: usos de si na pandemia

Nos enunciados da professora Fernanda (E1), observamos suas posições axiológicas diante do tempo de dedicação ao trabalho e da intensidade laboral no contexto da pandemia: "a preparação das aulas leva um tempo maior", "o professor trabalha três vezes mais", "aula online rende mais, é mais rápida", "é desafiador a todo tempo", "um período curto para muitas adaptações". Suas reflexões, pautadas no diálogo com a sala de aula presencial, são marcadas por palavras, cujos acentos valorativos relevam sua relação com a atividade laboral, os anseios, expectativas ("a cada dia vou me sentindo mais segura e preparada") e receios ("se dá alguma coisa errada, a gente fica assustado, entra em desespero"). As infidelidades do meio exigem usos de si para gerir os impasses, o que vai revelando um sujeito-professor dinâmico, engajado com sua prática docente, embora se mostre no meio de um processo de novas experiências.

A mesma questão é apontada por Helivânia (E2), porém a professora não faz menção ao tempo aditivo de trabalho como os outros professores. Sua fala "[...] o fato de muita coisa ser cobrada, em um curto período de tempo [...]" endossa a relação da intensidade de trabalho e a exiguidade de tempo para desenvolvê-lo. Os acentos valorativos do enunciado apontam para aspectos da invisibilidade do trabalho no que se refere à ampliação das horas de dedicação, um debate de normas entre o que é cobrado e o tempo escasso para se fazer a tarefa, revelando aspectos da dramática de uso de si. No enfrentamento das infidelidades do meio, a professora se debate com o fato de ter de aprender novos modos de interação em uma jornada de horas de trabalho que excede a sua carga horária contratada.

Em relação aos excertos seguintes, podemos perceber o diálogo entre as posições dos professores no evento do ato enunciativo, em que as verbalizações focalizam as percepções dos docentes sobre o ensino remoto no cronotopo da pandemia. No enunciado de Vinícius (E3), "Os horários são os mesmos de antes da pandemia. Há mais trabalho porque precisamos preparar aulas em um outro formato", percebemos uma relação de concordância com Fernanda, ao, por um lado, associar às aulas presenciais e, por outro, considerar o mesmo tempo de trabalho para desenvolver uma atividade que exige outros domínios de conhecimento, ou seja, implica mais intensidade na preparação da aula.

Em relação à concordância pelo aumento de horas de trabalho, isso também se dá com os dizeres de Rafael (E4): "O volume de trabalho aumentou bastante depois do regime de aulas a distância". Como em Helivânia (E2), há na verbalização de Rafael índices da invisibilidade do trabalho ao acentuar valorativamente o "volume" de trabalho em relação ao mesmo tempo do ensino presencial. Logo, o professor depreenderá ainda mais horas de seu dia para realizálo, pois não estava na rotina do professor dar aulas online.

No evento do ato, cada docente enuncia sobre a sua atividade, deixando perpassar diferentes vozes sociais no seu discurso, que se aproximam de uns e se distanciam de outros. Os docentes sinalizam nos depoimentos outras demandas a que são convocados, que não deixam de interferir nas suas práticas docentes. Rafael e Vinicius afirmam que têm responsabilidades de ajudar com as tarefas de casa, o que indica a diversidade de afazeres e o aumento da 
intensidade da atividade docente. Helivania, por sua vez, trata dos desafios de ter de se dividir entre o trabalho docente e o papel de mãe de um filho pequeno, que também teve as aulas cessadas. Tais desafios apontam para os usos de si do professor que, ao trabalhar no sistema home office, além de se deparar com as exigências impostas pelas tecnologias e novas formas de interação, incluindo cobranças da comunidade escolar, como de alguns pais, por exemplo, se confronta com as funções da casa, da maternidade etc., revelando a ampliação de ansiedades e desafios no cotidiano. Nesses embates dialógicos, percebemos aspectos das dramáticas de uso de si dos professores, em que o debate de normas e valores não esconde a tensão entre os saberes instituídos (formação) e os investidos (prática) na atividade laboral, que se ampliam, complexificam e se entranham nos diferentes lares.

As tecnologias e os desafios da formação: usos de si na pandemia

Nas verbalizações em foco, a preocupação com o uso das novas tecnologias, plataformas de ensino e a dificuldade em esclarecer de que modo trabalham, perpassa a fala de todos os professores e são usadas diferentes designações para nomear as aulas a distância, como "sistema remoto" (E1) e "regime de aulas a distância" (E4), o que sinaliza o caráter emergencial da metodologia de ensino ofertado, ao qual professores e alunos foram submetidos.

A professora Fernanda (E1), ao acentuar valorativamente o rendimento da aula online ("Temos que fazer slides e criar mais exercícios, porque a aula online rende mais, é mais rápida"), abre espaço para se discutir o quanto a tecnologia impacta no desenvolvimento das aulas. Tal valoração sinaliza que o tempo em sala de aula virtual não é o mesmo tempo da sala de aula presencial, acarretando aumento nas horas de preparação de material, mais horas de trabalho empreendidas. A partir da posição axiológica da docente, podemos entender que há muito mais desgaste no processo de preparação do material para ser exposto ao aluno na tela, do que propriamente pela aula em si, ou seja, pelo momento sincrônico que ocorre a aula online. Se as tecnologias, de certo modo, facilitam as interações online, de outro, exigem conhecimento para usá-las adequadamente, o que remete à necessária formação para esse fim.

Sobre as tecnologias, a docente (E1) observa ainda que há diferentes domínios entre os professores: "Há professores mais novos que dominam muito bem a tecnologia, mas há também professores que não dominam nada. Eu vejo que é desafiador a todo tempo". A valoração dos que dominam as tecnologias recai para os mais jovens, que podem ser associados aos nativos digitais (PRENSKY, 2001) e, por isso, sairiam favorecidos nessa situação de trabalho com as aulas remotas. Já teriam uma formação, ao nascerem numa sociedade digital, pela prática, para o uso das tecnologias. Por sua vez, ao acentuar valorativamente que há "professores [que] não dominam nada", é possível associar aos imigrantes digitais (os não nativos digitais), que, como o próprio nome diz, imigraram de uma fase a outra, da analógica para a digital. Essa "categoria" teria uma outra cultura escolar, menos autônoma. Entretanto, existem nativos digitais que, por escolha voluntária, não têm interesse no domínio das tecnologias ou condições financeira de possuir um smartphone ou computador, o que pode contemplar alguns casos de professores que não dominam muito as tecnologias, ou 'nada', como trata Fernanda.

As dramáticas de uso de si de Fernanda vão aparecendo no decorrer do depoimento. Quando a docente afirma a maior dificuldade com a tecnologia no início do ensino remoto - "Foi difícil no começo, mas agora estamos começando a dominar melhor os instrumentos tecnológicos para promover aulas mais significativas para os alunos" - percebemos o uso de si pelo outro, que exigiu, em curto espaço de tempo, a adaptação à modalidade remota, independentemente do domínio ou não das tecnologias pela professora. Os acentos valorativos engendrados na verbalização indicam os usos de si por si da professora ao sentir-se, por um lado, desafiada ("foi difícil no começo") e, por outro, capaz de usar as ferramentas tecnológicas em 
suas aulas ("Mas a cada dia vou me sentindo mais segura e preparada").

Observamos acentos valorativos nas palavras da professora Helivânia (E2) no que tange às dramáticas de usos de si em relação à tecnologia: "Existe a dificuldade em aprender a utilizar novas ferramentas e o fato de muita coisa ser cobrada, em um curto período de tempo". Essa dificuldade em "aprender e utilizar" está atrelada à falta de formação para o manuseio dos recursos educacionais e digitais que ilustram algumas perspectivas adversas nesse cenário emergencial e de aulas remotas. O professortrabalhador, que tem um papel central para pôr em prática o ensino remoto, é desafiado, em um pequeno espaço de tempo, a dominar as tecnologias. O rigor das normas, em situação emergencial, põe em relevo a dificuldade que pode abarcar tanto os imigrantes digitais quanto os nativos.

Nas verbalizações dos docentes Vinicius (E3) e Rafael (E4), há tons expressivos voltados para usos de si também ligados à tecnologia. Para Vinicius, o uso das tecnologias remete a mais trabalho: "Há mais trabalho porque precisamos preparar aulas em um outro formato". Para Rafael, a intensidade de expressar suas dramáticas é mais contundente, se comparada a Vinicius: "O volume de trabalho aumentou bastante depois do regime de aulas a distância". Os acentos valorativos refletem e refratam as dificuldades enfrentadas com o uso das tecnologias, como é o caso do aumento do trabalho, a necessidade de "aprender a utilizar muitas ferramentas", sinalizando a falta de formação para o uso das tecnologias, e o desafio de fazer atividades online ("sem falar que o formato das atividades feitas a distância é bastante diferente das feitas em sala de aula e isso é bastante desafiador".

Além dos desafios apresentados, Rafael destaca como "a maior desvantagem", no contexto do ensino remoto, o fato de que "o acesso à internet ainda é limitado para alguns alunos, principalmente de baixa renda". Essa observação remonta os Parâmetros Curriculares Nacionais (PCNs), publicados em 1997, que assinalavam o problema das condições desiguais das escolas para o uso de tecnologias, o que podemos ampliar hoje para o acesso à internet à comunidade escolar: "a menção ao uso de computadores, dentro de um amplo leque de materiais, pode parecer descabida perante as reais condições das escolas, pois muitas não têm sequer giz para trabalhar" (BRASIL, 1997, p. 68).

Cabe ressaltar que, no que se refere à atividade docente, a partir do que é discutido nos PCNs, se, por um lado, o professor considera esse documento importante para a prática docente, por outro lado, hoje, com a realização das aulas remotas (síncronas e assíncronas) dentro do espectro das tecnologias ou fora dele, os desafios, limitações, lacunas e superações entram em confronto com os PCNs, já que a emergencialidade sobre o agir do professor na pandemia não permite uma formação "como um processo reflexivo e crítico sobre a prática educativa" (BRASIL, 1997, p. 25).

No mundo das normas e prescrições sobre o trabalho docente, pouco há sobre o uso de tecnologias na escola. A Base Nacional Comum Curricular (BNCC), de 2016, ao buscar conectar alunos e professores às tecnologias nas políticas educacionais, trata, em sua quinta competência, das tecnologias digitais, observando a necessidade de "compreender, utilizar e criar tecnologias digitais de informação e comunicação de forma crítica, significativa, reflexiva e ética nas diversas práticas sociais (incluindo as escolares)" (p. 09). Ainda que essas considerações possam ser consideradas um avanço, pouco foi feito nesse sentido para a formação dos professores, que, conforme a BNCC, seria um direito de todos: a "educação deve afirmar valores e estimular ações que contribuam para a transformação da sociedade, tornando-a mais humana, socialmente justa [...]".

Essas ponderações trazem à tona o conflituoso debate de normas e valores engendrado nas dramáticas de usos de si dos professores. Podemos dizer, seguindo a abordagem ergológica, que as normas são necessárias para o desenvolvimento do trabalho, mas que nunca vão corresponder em sua integralidade ao que acontece no real da atividade. No cronotopo da pandemia, que impôs um regime de ensino remoto emergencial, foram potencializadas as 
lacunas das normas, visto que antes da pandemia não havia exigência no ensino da educação básica por meio de vias digitais. Com isso, diante da necessidade emergencial, novas normas foram criadas e, ao mesmo tempo, os professores renormalizaram a prática docente. Entendemos, por conseguinte, que os impasses impostos aos professores não relativizam a atividade docente, mas sim, pelo contrário, mostram a complexidade do fazer industrioso, que é agravado com a pandemia.

\section{Considerações finais}

Esta reflexão, com base na perspectiva dialógica do discurso e na abordagem ergológica do trabalho, teve o objetivo de analisar características das dramáticas de usos de si de professores que assumiram o ensino remoto emergencial diante da pandemia do novo coronavírus. Nesse cenário, foram analisados quatro depoimentos de docentes do ensino básico, publicados em reportagens do G1 e do UOL, a partir de dois pontos complexos: (i) o tempo e a intensidade do trabalho, e (ii) as tecnologias e os desafios da formação.

Quanto ao tempo e a intensidade do trabalho, foi possível apreender pelos acentos valorativos dos enunciados que os usos de si dos docentes são voltados para o impasse entre a exiguidade de tempo e o aumento do trabalho devido às exigências emergenciais, que envolvem muitas (re)adaptações no fazer industrioso docente. A mudança do ensino presencial para 0 remoto não considerou a necessidade de novas habilidades e, consequentes, aprendizagens dos professores, o que permite dizer que houve um aumento significativo da dedicação do professor. Mais usos de si foram sendo impostos. Por um lado, houve mais exigências das instituições de ensino, famílias e alunos e, por outro, dos próprios docentes, que tiveram de renormalizar suas práticas laborais e redefinir a relação com o espaço familiar em casa.

No que tange ao segundo eixo, as tecnologias e os desafios da formação, pudemos observar o quanto as tecnologias se impuseram como necessárias para o desenvolvimento das aulas a distância. Diferentes níveis de intimidade com as tecnologias digitais foram revelados, refletindo e refratando variados modos de enfrentar os impasses vividos. A falta de formação voltada para o uso da tecnologias pôs à prova intensos usos de si dos professores que, se, de um modo, são convocados a trabalhar com as tecnologias digitais, de outro, se deparam com a falta de preparação adequada e, ao mesmo tempo, com a falta de tempo para uma formação crítica e reflexiva que possa contribuir com a transformação da sociedade, de modo a torná-la mais humana e justa, como prevê a BNCC.

As reflexões desenvolvidas colaboraram para se (re)conhecer as atividades docentes, em especial o quanto os professores são exigidos a se reinventarem nas suas práticas laborais neste período tão singular por que estamos passando. Também contribuíram para se pensar em medidas a serem tomadas no póspandemia, como uma formação contínua, alinhada com as exigências da sociedade. Ainda que o ensino remoto emergencial tenha trazido muita ansiedade e desafios aos professores, não deixou de mostrar a potencialidade do bom uso das tecnologias digitais, como dito por um dos professores para além dos depoimentos analisados: "[...] as vantagens são a possibilidade de levar uma diversidade maior de opções de conteúdos para o estudante. É possível ensinar sobre um assunto e ir bem além do livro e caderno" (Rafael).

Podemos compreender, em acordo com a perspectiva dialógica e a abordagem ergológica, que entendem, respectivamente, o ato ético, responsável e responsivo, como singular, e a atividade de trabalho como industriosa, irreproduzível, que o ofício da profissão perante as adversidades enfrentadas the confere plasticidade, movimentos dialógicos inusitados. O tempo todo o docente mostra a sua alteridade diante do outro, colegas, alunos, instituição, tecnologias etc., ou seja, ele se altera nas interações, o que reitera a capacidade ativa de (re)adaptação singular, característica comum no exercício da atividade.

Embora o cenário do ensino pandêmico tenha refletido e refratado entranhas das dramáticas de uso 
de si dos docentes em relação com os saberes investidos e instituídos na atividade, também mostrou - quanto as inquietações são criadoras e transformadoras. Os professores, como sujeitos dialógicos e ativos, vão instaurando novos meios de ensino-aprendizagem, novas metodologias, novas práticas. Nesse exercício, parafraseando Paulo Freire (2020), o professor vai movendo-se com curiosidade para, na inquietude e na busca, aprender e ensinar. Aprender, fazer parte da sua contínua formação, e, ao mesmo tempo, ensinar, proporcionar uma educação humanizada, emancipadora. Essa concepção pode ser inter-relacionada com a proposta da ergologia que busca compreender o trabalho para transformá-lo. Em tal movimento dialógico, associamos compreender e transformar a "esperançar", inspirando-nos em Freire (1987, p. 58), para assinalar o enfrentamento da realidade, na concretude histórica, agindo de forma a mudar uma dada situação: "No momento em que a percepção crítica se instaura, na ação mesma, se desenvolve um clima de esperança e confiança que leva os [indivíduos] a empenhar-se na superação das 'situações-limites'”.

\section{REFERÊNCIAS}

ABED. Associação Brasileira de Educação a Distância. Disponível em <http://www.abed.org.br/site/pt/> Acesso em: 01 de ago. de 2020.

AMIGUES, René. Trabalho do professor e trabalho de ensino. In: Machado, A. R. (org.). O ensino como trabalho: uma abordagem discursiva. Londrina: Eduel, 2004.

BAKHTIN, M. Os gêneros do discurso (1952-1953). Organização, tradução, posfácio e notas de Paulo Bezerra. Notas da edição russa de Serguei Botcharov. Rio de Janeiro: Editora 34, 2017. BAKHTIN, M. O discurso no romance. In: Teoria do romance I: A estilística. Tradução Paulo Bezerra. São Paulo: Editora 34, 2015.

BAKHTIN, M. Estética da criação verbal (1979). Tradução de Paulo Bezerra. 6. ed. São Paulo: Martins Fontes, 2011.

BAKHTIN, M. Problemas da poética de Dostoiévski (1963). Tradução de Paulo Bezerra. Rio de Janeiro: Forense, 2010.
BAKHTINE, M. Pour une philosophie de l'acte (19201924/1986). Tradução de Ghislaine C. Bardet. Paris: Editions L'Age d'Homme, 2003.

BRASIL. Parecer CNE/CP n‥ 9/2020. DF, 2020.

Disponível em

$<$ http://portal.mec.gov.br/index.php?option=com_doc man\&view=download\&alias $=147041-$ pcp009-

20\&category_slug=junho-2020-pdf\&ltemid=30192>

Acesso em: 05 de ago. de 2020.

BRASIL. Base Nacional Comum Curricular. DF, 2016. Disponível em

$<$ http://basenacionalcomum.mec.gov.br/images/BNCC EEl_EF_110518_versaofinal_site.pdf> Acesso em: 05 de ago. de 2020.

BRASIL. Parâmetros Curriculares Nacionais. DF, 1997. Disponível em

<http://portal.mec.gov.br/seb/arquivos/pdf/livro01.pdf> Acesso em: 05 de ago. de 2020.

DI FANTI, M. G. C. Questões de (in)visibilidade: linguagem e trabalho. Desenredo, v. 15, p. 350-369, 2019.

DI FANTI, M. G. C. Ethos e ato ético: o discurso intolerante em redes (sociais) de sentidos. Projeto de pesquisa. CNPq, 2017.

DI FANTI, M. G. C. Linguagem e trabalho: diálogos entre estudos discursivos e ergológicos. Letras Hoje, Porto Alegre, v. 49, n. 3, p. 253-258, jul./set. 2014. DI FANTI, M. G. C. Linguagem e trabalho: diálogo entre a translinguística e a ergologia. Desenredo, v. 8, p. 309-329, 2012.

DURRIVE, L. L'expérience des normes. Comprendre l'activité humaine avex la démarche ergologique. Toulouse: Octarès Éditions, 2015.

FAÏTA, D. O desenvolvimento de uma situação do trabalho docente no diálogo entre professores: uma atividade discursiva sobre a atividade educativa. Trad. Maristela Botelho França. In: Di Fanti, M. G.; França, M.; Vieira, M. (org.) Análise dialógica da atividade profissional. Rio de Janeiro: Express, 2005, p.117145.

FAÏTA, D. Análise das práticas linguageiras e situações de trabalho: uma renovação metodológica imposta pelo objeto. In: Souza-e-Silva, M. C. P. e Faïta, D. (org.), Linguagem e trabalho: construção de objetos de análise no Brasil e na França. Tradução de Inês Polegatto e Décio Rocha. São Paulo: 2002. p. 45-60.

FARACO, C. A. Linguagem \& diálogo: as ideias linguísticas do Círculo de Bakhtin. São Paulo: Parábola Editorial, 2009.

FRANCO, G. Coronavírus: professores falam dos desafios e vantagens de trabalhar em casa. UOL. <https://educador.brasilescola.uol.com.br/noticias/cor onavirus-professores-falam-dos-desafios-evantagens-de-trabalhar-em-casa/33270.html> Acesso 21 de ago. 2020. 
FREIRE, P. Pedagogia da autonomia: saberes necessários à prática educativa (1996). 63. ed. Rio de Janeiro/São Paulo: Paz e Terra, 2020.

FREIRE, P. Pedagogia do oprimido. 17. ed. Rio de Janeiro: Paz e Terra, 1987.

<file:///F:/20.\%20textos\%20originais/Paulo\%20Freire/ Pedagogia\%20do\%20oprimido\%20-

\%20Paulo\%20Freire\%20-\%201970.pdf> Acesso: em 25 de ago. de 2020.

HINZ, J. R.; DI FANTI, M. G. C. O trabalho do professor-estagiário de língua portuguesa: uma atividade direcionada a quem? Alfa (Unesp), v. 57, p. 315-339, 2013.

IBGE. Instituto Brasileiro De Geografia e Estatística. Disponível em

<https://agenciadenoticias.ibge.gov.br/> Acesso: em 03 de ago. de 2020.

LEITE, M. A.; VOGES, M. C. N. (org.). Linguagem e Tecnologia. In: A afetividade e o trabalho na educação a distância. Belo Horizonte: Tradição Planalto, 2020. p. 13-28.

MACHADO, I. B.; DI FANTI, M. G. C. Da criação de espaços de dizer: (re)normalizações e usos de si no trabalho. Moara, v. 1, p. 21-36, 2013.

MEDVIÉDEV, P. O método formal nos estudos literários: introdução crítica a uma poética sociológica (1928). Tradução de Sheila Camargo Grillo e EkaterinaVólkova Américo. São Paulo: Contexto, 2012.

MENDEZ, B. Professores relatam mais trabalho em nova rotina de ensino pela internet durante pandemia. G1. <https://g1.globo.com/mg/sul-deminas/noticia/2020/06/08/professores-relatam-maistrabalho-em-nova-rotina-de-ensino-pela-internetdurante-pandemia.ghtml> Acesso 21 ago. 2020. PRENSKY, M. Digital Native, digital immmigrants. Digital Native immigrants. On the horizon, MCB University Press, v. 9, n. 5, October, 2001. Disponível em: <https://marcprensky.com/writing/Prensky\%20\%20Digital\%20Natives,\%20Digital\%20Immigrants\%2 0-\%20Part1.pdf> Acesso em: 05 de ago. de 2020. SAUJAT, F. O trabalho do professor nas pesquisas em educação: um panorama. Tradução de Anna Rachel Machado. In: Machado, A. R. (org.). O ensino como trabalho: uma abordagem discursiva. São Paulo: Eduel, 2004. p.3-34.

SCHWARTZ, Y. Uma entrevista com Yves Schwartz. Realização de Maria da Glória Corrêa di Fanti e Vanessa Fonseca Barbosa. Letrônica, v. 9, n. esp., 2016, p. 222-233.

SCHWARTZ, Y. Motivações do conceito de corpo-si, atividade, experiência. Tradução de Adail Sobral.

Letras de Hoje, Porto Alegre, v. 49, n. 3, p. 259-274, 2014.

SCHWARTZ, Y. Conceituando o trabalho, o visível e o invisível. Tradução de Cristine Vargas Pereira e Roseli Figaro. Trabalho, Educação e Saúde, Rio de Janeiro, v. 9, s. 1, p. 19-45, 2011.
SCHWARTZ, Y. A linguagem em trabalho. Tradução de Maria Cecília Pérez de Souza-e-Silva e Décio Rocha. In: Schwartz, Y.; Durrive, L. (Org.). Trabalho \& ergologia: conversas sobre a atividade humana. Coord. da tradução e revisão técnica de Jussara Brito e Milton Athayde. Niterói: EdUFF, 2010. p. 131-148. SCHWARTZ, Y.; DURRIVE, L. (Org.). Trabalho \& ergologia: conversas sobre a atividade humana. Coord. da tradução e revisão técnica de Jussara Brito e Milton Athayde. Niterói: EdUFF, 2010.

TARDIF, M. Saberes docentes e formação profissional. 17. ed. Petrópolis, RJ: Editora Vozes, 2017.

VOLÓCHINOV, V. A palavra na vida e a palavra na poesia (1926): ensaios, artigos, resenhas e poemas. Organização, tradução, ensaio introdutório e notas de Sheila Grillo e Ekaterina Vólkova Américo. São Paulo: Editora 34, 2019.

VOLÓCHINOV, V. Marxismo e filosofia da linguagem: problemas fundamentais do método sociológico na ciência da linguagem (1929). Tradução, notas e glossário de Sheila Grillo e Ekaterina Vólkova Américo; ensaio introdutório de Sheila Grillo. São Paulo: Editora 34, 2017.

WEISER, M. The Computer for the Twenty-First Century. Scientific American. September. 1991. p. 94104. Disponível em < https://www.Iri.fr/ mbl/Stanford/CS477/papers/WeiserSciAm.pdf> acesso em: 03 de ago. de 2020.

VOGES, Márcia Cristina Neves; DI FANTI, Maria da Glória Corrêa. Usos de si no ensino remoto emergencial: A atividade docente sob os enfoques dialógico e ergológico. Signo, Santa Cruz do Sul, v. 46, n. 85, jan. 2021. ISSN 1982-2014. Disponível em: $<$ https://online.unisc.br/seer/index.php/signo/article/view/ 15653>. doi:https://doi.org/10.17058/signo.v46i85.15653. 